2018-03

The Silencing of the Knowledge-base in Early Childhood Education and Care Professionalism

\title{
Campbell-Barr, Verity
}

http://hdl.handle.net/10026.1/10387

\subsection{0/09669760.2017.1414689}

International Journal of Early Years Education

Taylor \& Francis (Routledge)

All content in PEARL is protected by copyright law. Author manuscripts are made available in accordance with publisher policies. Please cite only the published version using the details provided on the item record or document. In the absence of an open licence (e.g. Creative Commons), permissions for further reuse of content should be sought from the publisher or author. 
"This is the author's accepted manuscript. The final published version of this work (the version of record) is published by [Taylor and Francis] in [nternational Journal of Early Years Education] available at: [10.1080/09669760.2017.1414689]. This work is made available online in accordance with the publisher's policies. Please refer to any applicable terms of use of the publisher."

\title{
The Silencing of the Knowledge-base in
}

\section{Early Childhood Education and Care Professionalism}

\begin{abstract}
It is widely accepted that the early childhood education and care (ECEC) workforce is central to the quality of services. Modernist constructs of quality signal the importance of qualifications for quality, but the preoccupation with qualification levels silences questions about the knowledge required of ECEC professionals. Postmodern perspectives have opened up debates on understandings of professionalism and given voice to those who work in ECEC. However, sociological perspectives of knowledge challenge postmodernism as either creating a dichotomy between modernist technocratic models of professionalism and the ethical models implicated in postmodernism or at worst present knowledge as non-existent. Adopting a sociological perspective of knowledge moves away from the dichotomy, enabling a critical consideration of what is the knowledge-base for ECEC, how it is formed, legitimised and applied. Drawing on Bernstein contributes to the debates on professionalism through providing a model for the ECEC knowledge-base that identifies multiple forms of knowledge, representing both theoretical and experiential knowledge. Theoretical knowledge has strong boundaries that provides legitimacy. However, whilst the social origins of experiential knowledge offers legitimacy,, it requires greater articulation and scrutiny.
\end{abstract}

Key Words: knowledge, professionalism, modernism, postmodernism, sociology-of-knowledge 


\section{The Silencing of the Knowledge-base in}

\section{Early Childhood Education and Care Professionalism}

The Early Childhood Education and Care (ECEC) workforce is routinely demonstrated as central to the quality of ECEC (e.g. (Fukkink and Lont 2007; Jones 2014; Urban 2012), but in this paper I discuss whether different constructions of quality and professionalism have silenced a consideration of what the ECEC knowledge-base is. Modernist constructs of quality focus on qualification levels rather than considering the knowledge obtained via the qualifications and whilst postmodernism highlights the limitations of modernism, the deconstruction of the empirical knowledge-base creates uncertainty as to what those working in ECEC are expected to know. Whilst postmodern perspectives foreground a more ethical construct of professionalism (e.g. Dahlberg and Moss 2005), the associated knowledge-base struggles for legitimacy. Drawing on Bernstein (1999; 2000), a model of the ECEC knowledge-base that incorporates multiple forms of knowledge, representing both the empirical and ethical constructs of ECEC professionalism, is proposed. The focus on the knowledge-base emphasises the socio-epistemic properties of different kinds of knowledge, from the theoretical to the everyday, which represent the store of information that those in ECEC draw upon to guide their work with children. However, there remains a need to further articulate the theoretical and philosophical origins of the ECEC knowledge-base.

The discussion is framed by the international interest in the quality of ECEC and the associated interest in the ECEC workforce. The international dimension presents a clear challenge as ECEC represents a broad and diverse range of services. Defining ECEC as encompassing services for children from birth to the start of school, the inevitable diversity in the workforce at the international level is evident, shaped by national requirements, policy interests and socio-historical constructions of ECEC services and those who work in them (Oberhuemer 2014). A clear challenge is that a generic conception of the ECEC workforce masks the structural and socio-cultural differences that exist internationally. Focussing on the ECEC knowledge-base is not about creating a generic set of standards and principles in an attempt to mask the divergence that is present in ECEC workforce requirements. Rather, I consider how explorations of qualification levels, standards and competency profiles, and interpretations of the meaning and understanding of professionalism, have drawn attention away from considering what the knowledge-base is for working in ECEC. Throughout the discussion I use 'ECEC workforce' to represent the structural differences in the qualification requirements of those who work in ECEC, whilst using 'professionalism' to symbolise explorations of the knowledge, skills and attitudes that are expected of those who work in ECEC. I, like others, have been drawn to postmodernism (more specifically poststructuralism) for 
questioning how ECEC quality and the associated professionalism of those who work in ECEC has been defined through modernist approaches that seek objectivity, reliability and predictability. Modernist constructs reflect power inequalities that favour the 'know and fix' mentality of policy makers and silence the views and experiences of ECEC professionals (e.g. Dahlberg and Moss 2005; Osgood 2010; Van Laere et al 2012). Postmodern approaches will be demonstrated as being important for considering the silenced knowledge of ECEC professionals, particularly in relation to what is missed in constructs of quality and professionalism. However, postmodern perspectives will also be challenged through sociological perspectives of knowledge that have questioned what knowledge is and how it is formed and legitimised. Whilst initially there appears to be an overlap with postmodern perspectives, sociologists question whether in is most extreme, postmodernism presents knowledge as being non-existent (Young 2007). Sociological perspectives focus on the knowledge-base in order to explore the multiple forms of knowledge for ECEC (and other professions) and the formation, legitimisation and relationship to practice of knowledge. The sociology of knowledge perspective considers the experiential and social basis of knowledge as providing a foundation for an ECEC knowledge-base.

I begin with an overview of the debates on quality ECEC before focussing on the workforce and professionalism. The discussion of the ECEC workforce considers how qualifications are structured in different international contexts, their content and the related terminology used to describe members of the workforce. I then contrast technocratic models of professionalism, informed by top down, bureaucratic processes that favour observable and knowable attributes with models of professionalism that foreground a more ethical construct, derived from practitioner perspectives and encompassing more tacit forms of knowledge. Whilst there appears to be a dichotomy between the different models of professionalism, I propose a framework that brings together different forms of knowledge, with different processes of acquisition and validation, to open up a discussion on a knowledge-base for ECEC.

\section{Quality Early Childhood Education and Care}

Quality ECEC has become a policy project for supranational organisations such as the OECD and European Commission, due to the increasing evidence base that demonstrates the importance of quality for supporting the development of children from socioeconomically disadvantaged groups (Cohen and Korintus 2016; White 2011). Since the 1960s there have been three waves of research into quality ECEC (Dalli 2014). The first focused on whether childcare was bad for children, the second aimed to identify elements that could be manipulated to produce high quality care and the third adopted a more ecological approach. Foucauldian perspectives have also explored how empirical research investigating the quality of ECEC between 1980 and 2008 has developed from perspectives of quality as an objective reality to 
more ecological perspectives (Fenech 2011). The former, demonstrates the influence of positivist paradigms and the development of assessments of quality, such as Early Childhood Environment Rating Scale (ECERS) for children from two and half to five years. ECERS (and other related tools) consists of a series of subscales under which are a list of items that are judged against statements that relate to a seven point grading system. The scales are symptomatic of the influence of positivist research paradigms in developing mechanisms for measuring and assessing the quality of ECEC. Quality assessments, such as ECERS, are focused primarily on structural quality, whilst ecological perspectives have sought to identify connections between structural and process quality (Dalli 2014; Fenech 2011). The ecological approach also began a more philosophical approach to quality through asking questions of who and what defines quality (Dalli 2014).

ECERS has become a global tool for assessing quality, as illustrated by the Effective Provision of Preschool Education (EPPE) project where it was used (along with an extension to the scale) to demonstrate the quality of ECEC in association with child outcomes in England (Sylva et al. 2004). The EPPE project has been considerably influential in the English context and beyond (Georgeson and Payler 2014) for shaping the direction of ECEC policy, such as developments in quality standards and ECEC training. Recently EPPE (now The Effective Pre-School, Primary and Secondary Education - EPPSE project) has been supplemented by a cost benefit analysis (Catton et al. 2014). The study (Catton et al. 2014) is illustrative of a trend to demonstrate the economic effectiveness of ECEC, whereby investments in ECEC are deemed to yield economic returns as a result of reduced future social expenditure that are the consequences of disadvantage, alongside improved economic activity amongst children on their entering adulthood (Heckman 2000; Heckman and Raut 2016). Graphical representations symbolise how the economic return of investing in education is highest when investing in ECEC, as opposed to any other stage of education. The importance of ECEC is not being questioned; economic assessments of value are compelling, with value likely to extend beyond that which is captured by economic assessments (Campbell-Barr 2012). However, assessments of quality, value and child outcomes are symptomatic of a positivist model of research concerned with finding associations between measurable attributes of ECEC provision and child outcomes.

The positivist paradigm frames most research about the quality of ECEC and is illustrative of modernist constructs of quality that seek objectivity and certainty through scientific knowledge (Dahlberg and Moss 2005). Modernist constructs of quality are criticised for their presumed rationality and the pervasive belief that it is "possible to establish reliable, value-neutral truths about a supposedly objective, real world" (Dahlberg et al. 2013: 20) . Postmodernism represents a broad camp, influenced by theorists such as Foucault, Deleuze and Derrida and is adopted here to represent the challenge to and disenchantment with 
modernity. Universal, rational and scientific truths are challenged for their presumed certainty and failure to capture a more holistic and ecological approach to human life (Dahlberg and Moss, 2005). A postmodern perspective does not dismiss positivist assessments of quality, but presents positivism as just one understanding of the complexities of the social world. Embedded in the mainstream quality construct of ECEC are a series of discursive truths about the normal child and desirable stages of child development, creating systemised knowledge and ways of speaking about children that govern the ways in which ECEC professionals work with children (MacNaughton 2005). The good ECEC worker is one who has the right practices at the right time to achieve the right outcomes (Dahlberg and Moss 2005), with policy developments around ECEC qualifications being about uniformity in the hope of predictability of outcomes. However, assessments of quality that focus on structural indicators, such as qualification levels, silence the knowledge-base (Fenech 2011) by not exploring how a qualification prepares an individual for working with children.

Existing research on the quality of ECEC (e.g. Mathers et al. 2007; Fukkink and Lont 2007) contributes to the widely accepted belief that ECEC training is the cornerstone of quality ECEC (Fukkink and Lont 2007; Jones 2014; Urban 2012). However, it is worth emphasising that it is not solely training that contributes to quality, as other variables will also contribute. For example, government proposals in England to adjust ratio levels if staff had higher qualifications, led researchers to respond with evidence that it was both ratios and qualifications that contributed to quality (Eisenstadt et al. 2013). Further, whilst the structural indicator of qualifications was a predictor of quality, it was demonstrated to be in association with the process indicators of staff interactions with children, demonstrating the multifaceted nature of quality.

\section{The focus on qualifications}

Despite the interest in quality ECEC and the ECEC workforce by surpa-national agencies, national governments and researchers, qualification requirements continue to vary internationally in regards to how they are constructed, what age children the qualifications focus on and whether they are (so called) care, education or educare in their focus. International ECEC systems are categorised by the governance of services as being either integrated or split (Lindeboom and Buiskool 2013). Split models structure the governance of services according to the age of the child, with services for children birth to three primarily being focused on care and within social welfare departments, whilst those for children from three to school age focus on education within education departments. Qualification requirements often vary as a result of the split, with a trend for those working in care services being required to have lower qualifications than those in education (Commission/EACEA/Eurydice/Eurostat. 2014). The structural 
differences are symptomatic of a historical divide between childcare and early education services that is evident in both Europe and North America, whereby care is associated with supporting working parents and early education provides the first step in lifelong learning (Moss 2006). Supra-national organisations such as the European Commission favour the integrated model (Cohen and Korintus 2016). However, a structural change to co-locate the governance of services does not always equate to integrated training models or status for those working with different age children, with persistent structural fragmentation (Cohen and Korintus 2016).

Further fragmentation exists in how services are conceptualised. In Australia, education focused ECEC services have a history of drawing on episteme (pure knowledge), whilst childcare services have centred on techne (technical skill) (Andrew 2015). Integrating care and education within training is not as simple as combining pure and technical knowledge, as the two have different epistemological basis.

Structural challenges in ECEC training also relate to the relationship with primary education. For example, France is regarded as having a long history of professionalism, supported by a strong relationship to primary education (Urban et al. 2012). France combines the training of those who will work in early education with those training to work in primary education. Whilst in France there is a requirement for a Masters qualification for working in early education, there are concerns that the connection to school results in too great a focus on academic scholarship (Garnier 2011). Moves to extend preschool education to two year olds have raised questions about the appropriateness of an academic focus for this age group (Garnier 2011), whilst neglecting to consider the position of those who have trained (at a vocational level) to work with children from birth to three. The French model draws attention to understandings of the ECEC knowledge-base both in regards to conceptualisations of education within ECEC services (and how these relate to primary education) and the child-age specifity of the knowledgebase. Specialist training, with age specific depth of coverage has been identified as important for ECEC (Early and Winton 2001), but there are questions as to the range of the age specific training and whether the ECEC knowledge-base is shared across different stages of ECEC and with those in primary education. Research exploring associations between the focus of Bachelor Degrees and the quality of ECEC found no differences in quality between those with an early childhood education or child development major (in the degree) and those with other education focused qualifications (Early et al. 2006). The evidence indicates that 'education' focused degrees are important and whilst there is no articulation of what 'education' is, there are implied negative associations for non-education degrees. In Finland, both Education and Social Sciences Bachelors are available for those training to work in ECEC (Karila 2008). The education focused training has been identified as better for the quality of ECEC due to the working orientations and skills of the practitioners (Oberhuemer et al. 2010; Urban et al. 2012). However, the use 
of the term 'education' is not favoured in all contexts. The official translation of Danish Professionsbachelo som paedagog is Bachelor in Social Education (Jensen 2016), presenting a seeming blend between social scientific and education focused training, but Jensen rejects the translation of 'social educator' in favour of 'pedagogue'. Evidently there are challenges in translation and how AngloAmerican terminology struggles with the use of pedagogue (Jensen 2016). Often pedagogue is translated as teacher or definitions fail to recognise that pedagogue within continental Europe has a broad interpretation of education, representing a holistic concept of education, care and upbringing (see Moss 2006). The use of pedagogue re-iterates questions about understandings of education in the ECEC knowledge-base and the epistemological foundations for ECEC training. Training requirements for those working in ECEC are therefore fragmented internationally and nationally as a result of structural, conceptual and discipline differences. The fragmentation is a clear challenge to forming a shared knowledge-base for ECEC (Hordern 2014).

\title{
More than a Qualification
}

Explorations of ECEC professionalism have looked to move beyond identifying the structural fragmentation of the ECEC workforce to consider who and what informs concepts of professionalism (Oberhuemer 2005; Oberhuemer et al. 2010; Urban 2008). There has been an attempt to consider both the 'epistemological hierarchy' (Urban 2008) that alienates those that work in ECEC from the construction of the knowledge-base and what is lost in modernist constructions of professionalism.

\begin{abstract}
In contexts where governments set the terms of the relationship and the professional community has limited influence, then we may find professional frameworks that mirror particular political concerns, perhaps reducing the time and curriculum space for those aspects of professional knowledge that may be prioritised by the broader professional community.
\end{abstract}

Hordern 2016: 511

The European Union's conceptualisation of lifelong learning, and associated ECEC professionalisation, illustrates how learning has become a process of skill validation (Vandenbroeck et al. 2013). Competence models, favoured by the European Union, embrace an individualised concept of the entrepreneurial self as a form of technocratic professionalism, but Vandenbroeck et al (2013) identify a counter discourse of a broader more reflective professionalism. For example, the Competence Requirements in Early Childhood Education and Care (CoRe) project (Urban et al. 2011) demonstrated how the terms competence and competent have more sophisticated meanings within ECEC than is indicated in national competency 
profiles, such as those found in the UK. The counter discourse resists the epistemological hierarchy and seeks a broader understanding of professionalism derived from within ECEC practice.

Empirical research considering the views of those who work in ECEC provides a broader concept of professionalism and signals the knowledge that is important to those who work in ECEC. In the English context, where there are continued efforts to upskill the ECEC workforce, professionalisation agendas are characterised by neo-liberal technicist models of professionalism imposed onto those that work in ECEC (Osgood 2009; Osgood 2010). Drawing on theories of performativity, Osgood (2010) demonstrates the tensions between the official, technocratic, surveillance of those working in ECEC and a more personal, moral and emotional construct of professionalism that comes from within the ECEC workforce. The conceptualisation of professionalism as requiring emotions and morals resonates with other research that identifies attitudes and dispositions as important. A survey of those working in ECEC in Sweden, Austria and Bulgaria to explore the socio-cultural differences in concepts of quality identified attitudes as the most important factor for the quality of preschool in Sweden and Austria, whilst being second to the child group size in Bulgaria (Brodin et al. 2015). Ground up approaches to exploring professionalism in Italy, that have been critical of technocratic models of professionalism, also identify a caring attitude as important (Balduzzi 2011). In Finland, attitudes have been identified as important for shaping approaches to pedagogical practice, particularly in terms of positive attitudes towards children, colleagues, parents and education (Happo et al. 2013), with an ethical attitude being important in the Swedish context (Kuisma and Sandberg 2008). Further, critical perspectives of a 'regulatory gaze' in relation to professionalism in England, identify that professionalism for those working in ECEC includes dispositions such as sensitivity and empathy (Miller 2008: 262). The studies adopt a range of research approaches (both quantitative and qualitative), but all draw on the perspectives of those training to or working in ECEC to identify a construction of professionalism that is outside of technocratic models. The practitioner research illustrates that for those within ECEC there is a distinct attitudinal component to the knowledge-base that has been silenced within technocratic approaches to professionalism.

Identifying a broad conceptualisation of the ECEC knowledge-base raises questions as to how different forms of knowledge are acquired for working in ECEC. Discussion on the balance between theory and practice in ECEC training demonstrates the continued efforts of countries such as Greece (Sarakinioti and Tsatsaroni 2015) and Denmark (Jensen 2016), for example, in grappling with how best to prepare those who will work in ECEC, whilst demonstrating a general appreciation for a need for practical experiences in ECEC for future members of the workforce. Working with children develops professionalism through experience (Kuisma and Sandberg 2008: 191). Analysis of the English undergraduate model has illustrated the process of learning from experiences, both in ECEC settings and whilst attending training, 
whereby individuals adjust their behaviours as they learn to become the 'right' person for the job (Colley 2006). Once in employment ECEC professionals develop practical wisdom from the daily encounters of working with children (Andrew 2015) as professionals use prior experiences in ECEC to inform subsequent ones. The workplace and its culture is an important aspect of building experience, but the professional expertise that are generated/required may not be explicitly expressed, symbolised by metaphors and patterns of beliefs (Karila 2008). At times, the lack of expression is due to a presumed existence of the expertise required, presenting practical wisdom as a set of innate characteristics (McGillivray 2008; Penn 2011). Research from England has demonstrated that prior experiences of caring are often privileged over more theoretical forms of knowledge amongst those undertaking ECEC training (Colley 2006; Skeggs 1997; Vincent and Braun 2011). However, not explicitly expressing experiential knowledge, along with presenting practical wisdom as a set of innate characteristics, renders them invisible in modernist constructs of professionalism that seek knowable features. Experiential knowledge risks being de-valued and silenced from conceptualisations of an ECEC knowledge-base.

The origins of a practical wisdom and the influence of attitudes in ECEC can be attributed to historical constructs of ECEC professionalism that draw upon attributes of being warm, kind and maternal (McGillivray 2008), based on a philanthropic concern of protecting vulnerable children (Georgeson and Payler 2014). There is a strong experiential aspect to these qualities, underpinned by a romantic construct of focussing on feelings and beliefs (Aslanian 2015) rather than rational thought. However, there is a variable vocabulary for how to express the knowledge that is beyond the empirical. The distinction between dispositions and attitudes is complex as the terms are used interchangeably, but the examples of the research presented above indicate that dispositions relate more to behaviours and attitudes are a way of thinking (Georgeson and Campbell-Barr 2015). Attitudes and dispositions are indicative of the emotional aspects of working with young children, reflecting a dual process of considering the emotional well-being of children and the emotional pressures of working in ECEC. Without wishing to undermine the importance of the former, research has raised the issue of emotional labour and its potential for exploitation (Andrew 2015; Colley 2006) and the complexities of learning emotional responses for working in ECEC (Cameron and Maginn 2008; Elfer 2013; Page and Elfer 2013). The emotional aspects of ECEC demonstrate both the complexities of learning to work in ECEC and a construct of an ECEC knowledge-base that extends beyond the technocratic.

An ethic of care has been presented as a counter discourse to technocratic professionalism as it is underpinned by an ethical responsibility and approach to working with children, as opposed to a model of rules of conduct (Dahlberg and Moss 2005). An ethic of care is about making ethical decision, grounded in the context and the responsibility and care for the other, rather than applying particular rules (Dahlberg 
and Moss 2005). 'Ethical' is not in a Kantian sense of universal ethical principles, derived from reason, that will guide those working in ECEC to know how to respond to different situations encountered in ECEC (Campbell-Barr 2017). The Kantian perspective assumes that there are rights and wrongs, whereas the notion of an ethic of care recognises the plurality of responses. The absence of rules positions the ethic of care (and the encompassing attitudinal and dispositional characteristics) as outside of modernist constructs of professionalism and illustrates the silencing of the knowledge-base that comes from ECEC professionals in the technocratic models of policy makers. However, the lack of a coherent language for the ethic of care limits its articulation and distribution.

\section{A Professional Knowledge-base}

The case for an ECEC knowledge-base could be considered at best dichotomous and at worst non-

existent. The dichotomy is apparent in the opposing constructions of professionalism between an ethic of care and technocratic models as the two approaches appear to reject one another. Technocratic professionalism is rejected for being too narrow an understanding of professionalism that fails to consider the complexities of ECEC through its top down construction, but a model that foregrounds ethics is seen to be too subjective and slippery for it to warrant legitimisation within modernist constructs. Further, the challenge to the discursive truths through postmodern accounts in its outermost form means there is no truth (Hordern 2014). At the most extreme knowledge does not exist in postmodern accounts, only the power of the elite to exert what they think should exist (Young 2007). Certainly postmodern perspectives have questioned the certainty of knowledge (Young and Muller 2014), but they are not to the extent that knowledge does not exist, instead presenting a critical awareness of knowledge construction and application (Campbell-Barr and Leeson 2016; MacNaughton 2005), combined with an emphasis on a more emotional and ecological approach to ECEC. However, two challenges remain in developing a more critical approach, firstly the construction of a knowledge-base that is not dichotomous and secondly, the identification of what the knowledge-base consists of.

Firstly, to consider a model of ECEC that is not dichotomous, I turn to the work of Bernstein, before reconsidering what constitutes the knowledge-base for ECEC. Bernstein was a sociologist who drew on the work of Durkheim to consider knowledge production in society, with an interest in professional knowledge. Durkheim identified the social origins of knowledge and how this provided a form of legitimisation for knowledge due to the need for common knowledge to bind people together (Young and Muller 2007). Durkheim identified a shift in the knowledge-base between sacred and profane societies, whereby sacred societies considered knowledge, expertise and a commitment to moral codes and ethics as important, but the fall of religion and the rise of a profane culture saw reason, individualism, 
entrepreneurialism and personal autonomy favoured (Grace 2014). Pertinent here is both the decline in moral codes and ethics in favour of reason, and the dichotomy that appears to be present, as these are symbolic of the divide between technocratic models of ECEC professionalism and those that foreground ethics. However, Young and Muller (2014) draw attention to a cryptic comment from Bernstein (2000: 85) regarding professionalism:

The construction of the inner was a guarantee for the construction of the outer. In this we can find the origin of the professions.

The inner and outer reflect the coming together of both theoretical and experiential knowledge, that can be applied to a model for the coming together of technocratic and ethical constructs of ECEC professionalism. Bernstein explored the construction of knowledge and the process for its legitimisation. Often it is assumed that only codified knowledge is important (and has legitimacy), whilst everyday knowledge is disregarded (symptomatic of modernist constructs of professionalism and quality), but Bernstein emphasised the need for both (Young and Muller 2014). Bernstein developed a model that recognised that professionals, such as those in ECEC, draw on multiple forms of knowledge, both that which is grounded in theory and that which comes from practice.

Bernstein developed Regions (2000), where different forms of knowledge come together and are recontextualised for the context. Regions draw upon past specialised knowledge (with a long history and recognition) and everyday knowledge, the former being referred to as Singulars and the latter Fields of Practice. Singulars, that at best represent academic knowledge, are a form of knowledge for its own sake. Singulars have appropriated a space, being a strong and autonomous form of knowledge, protected by boundaries and hierarchies (e.g. psychology) (Bernstein, 2000). However, professional knowledge is not just about propositions, as the ability to recall propositions does not constitute knowing, the propositions have to be applied to demonstrate professional knowledge (Winch 2014). Within Regions knowledge is recontextualised to meet the needs of the field (Young 2007). Regions are the interface between the Singulars and Fields of Practice, the latter being the everyday practice and the tying of knowledge to the context (Young 2007). Fields of Practice are the practical contexts, where professionals exercise knowledge and reasonable judgements that draw on their stock of specialised professional knowledge (Young and Muller 2014). The application of knowledge (that represented by Singulars) should not be confused with a simple process of application as professionals are required to evaluate which propositions are helpful (or not). Therefore professionals need to know how to evaluate the knowledge and how to apply it (Winch 2014). Both aspects of know how enable professionals to solve the problems of a Field of Practice. 
Bernstein also discussed the legitimacy of knowledge and its relationship to the knower. The strong boundaries of Singluars, provides them with a given rigour, but as they are recontextualised the boundaries of the knowledge find themselves weakened (Bernstein 2000). Whilst this demonstrates the dynamics of knowledge, it also emphasises the process of legitimisation. Knowledge that has strong boundaries can be described and therefore shared, the sharing being a part of the legitimisation, but as the boundaries are weakened the knowledge becomes more closely tied to the context and can become context dependent, lacking the ability to be shared and legitimised. Thus whilst the strong boundaries of Singulars enables them to be shared, the recontextualisation process means they become context dependent and the boundaries weaken. (An example would be when a Singular such as Psychology becomes fragmented through the development of sub-disciplines). In particular, knowledge that comes from practice that lacks articulation (such as beliefs, dispositions and attitudes) struggles to be shared and therefore evaluated as it has weak boundaries. However, the legitimisation of knowledge in this model favours positivist approaches, whereby the sciences are seen as a gold standard for evaluation, but given the earlier notion that knowledge is social and given legitimisation due to a need for a common body of knowledge that binds people together, then it is the social that will give rise to the legitimisation of beliefs, dispositions and attitudes as a form of knowledge for ECEC.

The social origins of attitudes, dispositions and beliefs provides potential for their legitimisation as a form of knowledge, but they require greater articulation to enable their identification and evaluation. The European Commission refers to the knowledge, skills and attitudes that are appropriate to the context in their Lifelong Learning agendas, recognising that they are drawn upon to varying extents to respond to the context. Knowledge, skills and attitudes could arguably relate to the theoretical, experiential and foregrounding of ethics in ECEC, to provide a multifaceted ECEC knowledge-base. Knowledge, skills and attitudes could be reconceptualised as 'knowledge, practices and values' in order to develop a more complex understanding of what is required of those who work in ECEC and to adopt a less individualised concept of the purpose of ECEC towards more collective aspirations (Urban et al. 2011). The interchanging of skills and attitudes with practices and values is symbolic of the need to articulate a common body of knowledge for ECEC, without getting caught up in semantic debates. However, both models include knowledge leaving the question of what knowledge is required for ECEC?

There is evidence of a common knowledge-base for ECEC informed by developmental psychology and joined by knowledge on how children learn and strategies for teaching and learning (Brock 2013; Urban et al. 2012; Wood 2007). Knowledge on attachments and more recently neuroscience also inform the knowledge-base (Aslanian 2015; Vandenbroeck and Peeters 2008). The theoretical knowledge creates an accepted vocabulary for the ECEC knowledge-base, whereby child development is fostered through 
child-centred, play-based approaches that support children's explorations and discovery, whilst meeting their needs (Wood 2007). However, the vocabulary and the associated knowledge needs articulation through a consideration of what child-centred or play-based (for example) really means for ECEC professionals? Child development offers an example of a form of knowledge that is deeply grounded in understandings of ECEC, but with postmodernism challenging the presumed linearity of child development, how do ECEC professionals 'know how' to draw on child development knowledge (both in relation to how to evaluate and how to apply it)? There is a need to refocus on what the ECEC knowledge-base is, through considering the multiple forms of knowledge that inform ECEC professionals and how they 'know how' in their daily practice.

\section{Conclusion}

Constructs of ECEC quality and professionalism have become caught in a dichotomy of modernist and postmodernist approaches, the latter criticising the former for its positivistic approach and presumed certainty, whilst postmodern accounts of quality and professionalism that look to foreground ethics lack articulation and legitimacy. The technocractic model of professionalism has been criticised as a mechanism for controlling those who work in ECEC and how they work with children. Quality and professionalism are identified as being formed by top down constructions that silence both a broader construction of the knowledge-base and the knowledge that comes from within ECEC. Whilst postmodern accounts do not necessarily reject positivistic assessments of quality and professionalism (instead demonstrating a need for critical awareness) they do challenge the certainty of the knowledgebase. A construction of a professional knowledge-base that recognises multiple forms of knowledge needs to articulate both what is understood by attitudes, morals and beliefs and question the meaning of theoretical knowledge. Theories of child development, for example, become regarded as prescriptive, but given the pervasive influence of child development in ECEC there is a need to develop a professionalism that considers how knowledge on child development combines with a foregrounding of ethics to enable ECEC professionals to make sense of their practice.

Bernstein provides a model that enables an understanding of the ECEC knowledge-base to draw on a long history of theoretical knowledge, whilst incorporating the knowledge that comes from practice. Whilst theoretical knowledge is privileged in the model as it is stronger and more rigorous, thus enabling its distribution; greater articulation of attitudes, beliefs, dispositions and values will contribute to the distribution and legitimisation of a broader construct of the ECEC knowledge-base. In considering the sociological character of knowledge as aligned with its epistemological base, then the knowledge-base for ECEC is constructed via a social process that encompasses theoretical history and the daily experiences of 
professionals. The different forms of knowledge required for ECEC merely have different structures and are at different stages of legitimisation. Importantly, Bernstein offers ECEC professionals autonomy in determining the legitimisation of knowledge as they will evaluate the knowledge that is useful and how it is best applied.

Clearly, ECEC professionalism is a combination of initial training, time in practice and continued professional development, it is not a fixed state. Exploring the knowledge-base therefore is not about defining it as a non-adjustable entity. The social character of knowledge highlights its fluidity. Rather, exploring the knowledge-base is to develop greater understanding of what it constitutes and how ECEC professionals give meaning to their daily practice. Exploring a knowledge-base for ECEC is not about masking the lack of consistency in the training requirements of those who work in ECEC, but about the social production of knowledge that encompasses the varied experiences of ECEC professionals. 


\section{References}

Andrew, Y. (2015). "What we feel and what we do: emotional capital in early childhood work." Early Years, 1-15.

Aslanian, T. K. (2015). "Getting behind discourses of love, care and maternalism in early childhood education." Contemporary Issues in Early Childhood, 16(2), 153-165.

Balduzzi, L. (2011). "Promoting professional development in Early Childhood Education and Care (ECEC) field: the role of welcoming newcomers teachers." Procedia - Social and Behavioral Sciences, 15, 843-849.

Bernstein, B. B. (2000). Pedagogy, symbolic control, and identity: Theory, research, critique (Revised Edition), Oxford: Rowman \& Littlefield.

Brock, A. (2013). "Building a model of early years professionalism from practitioners' perspectives." Journal of Early Childhood Research, 11(1), 27-44.

Brodin, J., Hollerer, L., Renblad, K., and Stancheva-Popkostadinova, V. (2015). "Preschool teachers' understanding of quality in preschool: a comparative study in three European countries." Early Child Development and Care, 185(6), 968-981.

Cameron, R. J., and Maginn, C. (2008). "The Authentic Warmth Dimension of Professional Childcare." British Journal of Social Work, 38(6), 1151-1172.

Campbell-Barr, V. (2012). "Early years education and the value for money folklore." European Early Childhood Education Research Journal, 20(3), 423-437.

Campbell-Barr, V. (2017). "Quality early childhood education and care - the role of attitudes and dispositions in professional development." Early Child Development and Care, 197(1), 45-58.

Campbell-Barr, V., and Leeson, C. (2016). Quality and Leadership in the Early Years, London: Sage.

Catton, S., Crawford, C., and Dearden, L. (2014). "The economic consequences for pre-school education and quality". London: Institute of Fiscal Studies.

Cohen, B. J., and Korintus, M. (2016). "Making connections: reflections on over three decades of EU initiatives in Early Childhood Education and Care (ECEC)." Early Years, 1-15.

Colley, H. (2006). "Learning to Labour with Feeling: Class, Gender and Emotion in Childcare Education and Training." Contemporary Issues in Early Childhood, 7(1), 15-29.

Commission/EACEA/Eurydice/Eurostat., E. (2014). Key Data on Early Childhood Education and Care in Europe 2014 Edition. Publications Office

of the European Union., Luxembourg.

Dahlberg, G., and Moss, P. (2005). Ethics and politics in early childhood education: London : RoutledgeFalmer.

Dahlberg, G., Pence, A., and Moss, P. (2013). Beyond quality in early childhood education and care: languages of evaluation, London: Routledge.

Dalli, C. (2014). OCCASIONAL PAPER 4-Quality for babies and toddlers in early years settings: TACTYC.

Early, D. M., Bryant, D. M., Pianta, R. C., Clifford, R. M., Burchinal, M. R., Ritchie, S., Howes, C., and Barbarin, O. (2006). "Are teachers' education, major, and credentials related to classroom quality and children's academic gains in pre-kindergarten?" Early Childhood Research Quarterly, 21(2), 174-195.

Early, D. M., and Winton, P. J. (2001). "Preparing the workforce: early childhood teacher preparation at 2- and 4-year institutions of higher education." Early Childhood Research Quarterly, 16(3), 285306.

Eisenstadt, N., Sylva, K., Mathers, S., and Taggart, B. (2013). "More Great Childcare: Research Evidence". City: Oxford/London: University of Oxford and Institute of Education. 
Elfer, P. (2013). "Emotional aspects of nursery policy and practice - progress and prospect." European Early Childhood Education Research Journal, 1-15.

Fenech, M. (2011). "An Analysis of the Conceptualisation of "Quality" in Early Childhood Education and Care Empirical Research: Promoting "Blind Spots" as Foci for Future Research." Contemporary Issues in Early Childhood(2), 102-117.

Fukkink, R. G., and Lont, A. (2007). "Does training matter? A meta-analysis and review of caregiver training studies." Early Childhood Research Quarterly, 22(3), 294-311.

Garnier, P. (2011). "The scholarisation of the French école maternelle: institutional transformations since the 1970s." European Early Childhood Education Research Journal, 19(4), 553-563.

Georgeson, J., and Campbell-Barr, V. (2015). "Attitudes and the early years workforce." Early Years, 35(4), 321-332.

Georgeson, J., and Payler, J. (2014). "Qualifications and quality in the early years foundation stage ", in J. Moyles, J. Payler, and J. Georgeson, (eds.), Early Years Foundations. Maindenhead: McGraw Hill Education.

Grace, G. (2014). "Professions, Sacred and Profane: Reflections upon the changing nature of professionalism". London: Routledge.

Happo, I., Määttä, K., and Uusiautti, S. (2013). "How do Early Childhood Education Teachers Perceive Their Expertise? A Qualitative Study of Child Care Providers in Lapland, Finland." Early Childhood Education Journal, 41(4), 273-281.

Heckman, J. (2000). Invest in the very young, Chicago, IL: Ounce of Prevention Fund and the University of Chicago Harris School of Public Policy Studies.

Heckman, J. J., and Raut, L. K. (2016). "Intergenerational long-term effects of preschool-structural estimates from a discrete dynamic programming model." Journal of econometrics, 191(1), 164175.

Hordern, J. (2014). "Knowledge, practice, and the shaping of early childhood professionalism." European Early Childhood Education Research Journal, 1-13.

Jensen, J. J. (2016). "The Danish pedagogue education", in M. Vandenbroeck, M. Urban, and J. Peeters, (eds.), Pathways to Professional Early Childhood Education. pp. 15-28.

Jones, P. (2014). "Training and Workforce Issues in the Early Years", in G. Pugh and B. Duffy, (eds.), Contemporary Issues in the Early Years London: Sage, pp. 255-272.

Karila, K. (2008). "A Finnish viewpoint on professionalism in early childhood education." European Early Childhood Education Research Journal, 16(2), 210-223.

Kuisma, M., and Sandberg, A. (2008). "Preschool teachers' and student preschool teachers' thoughts about professionalism in Sweden." European Early Childhood Education Research Journal, 16(2), 186-195.

MacNaughton, G. (2005). Doing Foucault in early childhood studies : applying poststructural ideas, London: Routledge.

Mathers, S., Sylva, K., Joshi, H., Hansen, K., Plewis, I., Johnson, J., George, A., Linskey, F., and Grabbe, Y. (2007). Quality of childcare settings in the Millennium Cohort Study. Department for Education and Skills, London.

McGillivray, G. (2008). "Nannies, nursery nurses and early years professionals: constructions of professional identity in the early years workforce in England." European Early Childhood Education Research Journal, 16(2), 242-254.

Moss, P. (2006). "Farewell to Childcare?" National Institute Economic Review, 195(1), 70-83.

Oberhuemer, P. (2005). "Conceptualising the early childhood pedagogue: Policy approaches and issues of professionalism." European Early Childhood Education Research Journal, 13(1), 5-16. 
Oberhuemer, P., Schreyer, I., and Neuman, M. (2010). Professionals in Early Childhood Education and Care Systems: European Profiles and Perspectives, Leverkusen Opladen: Barbra Budich Publishers.

Osgood, J. (2009). "Childcare workforce reform in England and 'the early years professional': A critical discourse analysis." Journal of Education Policy, 24(6), 733-751.

Osgood, J. (2010). "Reconstructing professionalism in ECEC: the case for the critically reflective emotional professional." Early Years: An International Journal of Research and Development, 30(2), $119-133$.

Page, J., and Elfer, P. (2013). "The emotional complexity of attachment interactions in nursery." European Early Childhood Education Research Journal, 21(4), 553-567.

Penn, H. (2011). "Quality in Early Childhood Services." McGraw Hill: Berkshire.

Sarakinioti, A., and Tsatsaroni, A. (2015). "European education policy initiatives and teacher education curriculum reforms in Greece." Education Inquiry, 6(3).

Skeggs, B. (1997). Formations of class \& gender: Becoming respectable, London: Sage.

Sylva, K., Melhuish, E., Sammons, P., Siraj-Blatchford, I., and Taggart, B. (2004). The effective provision of pre-school education (EPPE) project: Final Report: A longitudinal study funded by the DfES 19972004: Institute of Education, University of London/Department for Education and Skills/Sure Start.

Urban, M. (2008). "Dealing with uncertainty: challenges and possibilities for the early childhood profession." European Early Childhood Education Research Journal, 16(2), 135-152.

Urban, M. (2012). "Researching Early Childhood Policy and Practice. A Critical Ecology." European Journal of Education, 47(4), 494-507.

Urban, M., Vandenbroeck, M., Van Laere, K., Lazzari, A., and Peeters, J. (2012). "Towards Competent Systems in Early Childhood Education and Care. Implications for Policy and Practice." European Journal of Education, 47(4), 508-526.

Urban, M., Vandenbroek, M., Lazzari, A., Peeters, J., and van Laere, K. (2011). "Competence Requirements in Early Childhood Education and Care (CoRe)."

Vandenbroeck, M., and Peeters, J. (2008). "Gender and professionalism: a critical analysis of overt and covert curricula." Early Child Development and Care, 178(7-8), 703-715.

Vandenbroeck, M., Peeters, J., and Bouverne-De Bie, M. (2013). "Lifelong learning and the counter/professionalisation of childcare: A case study of local hybridizations of global European discourses." European Early Childhood Education Research Journal, 21(1), 109-124.

Vincent, C., and Braun, A. (2011). "II think a lot of it is common sense. ...' Early years students, professionalism and the development of a 'vocational habitus'." Journal of Education Policy, 26(6), 771-785.

White, L. A. (2011). "The Internationalization of Early Childhood Education and Care Issues: Framing Gender Justice and Child Well-Being." Governance-an International Journal of Policy Administration and Institutions, 24(2), 285-309.

Winch, C. (2014). "Know-how and Knowledge in the Professional Curriculum", in M. Young and J. Muller, (eds.), Knowledge, Expertise and the Professions. London: Routledge.

Wood, E. (2007). "Reconceptualising Child-Centred Education: contemporary directions in policy, theory and practice in early childhood." Forum, 49(1\&2), 119-134.

Young, M. (2007). Bringing Knowledge Back In: Routledge.

Young, M., and Muller, J. (2007). "Truth and truthfulness in the sociology of educational knowledge." Theory and Research in Education, 5(2), 173-201.

Young, M., and Muller, J. (2014). "From the Sociology of Professions to the Sociology of Professional Knowledge", in M. Young and J. Muller, (eds.), Knowledge, expertise and the professions 
London: Routledge. 